\title{
Effect of dielectric barrier discharge (DBD) plasma on the activity and structural changes of
}

\section{horseradish peroxidase}

\author{
Shanshan Dong ${ }^{1,2}$, Yunfang $\mathrm{Ma}^{1,2}$, Yunfei Li ${ }^{1,2}$, Qisen Xiang ${ }^{1,2 *}$ \\ ${ }^{1}$ College of Food and Bioengineering, Zhengzhou University of Light Industry, Zhengzhou, PR China; ${ }^{2}$ Henan Key \\ Laboratory of Cold Chain Food Quality and Safety Control, Zhengzhou, PR China
}

*Corresponding author: Qisen Xiang, College of Food and Biological Engineering, Zhengzhou University of Light Industry, No. 136, Kexue Road, Zhengzhou 450001, PR China. Email: xiangqisen2006@163.com

Received: 30 June 2021; Accepted: 26 August 2021; Published: 14 October 2021

(c) 2021 Codon Publications

OPEN ACCESS (c) (i) (을

RESEARCH ARTICLE

\begin{abstract}
As an emerging nonthermal technology, cold plasma has been used to inactivate endogenous enzymes that are responsible for enzymatic browning reaction of fruits and vegetables. This study aimed to investigate the inactivation effect of dielectric barrier discharge (DBD) plasma on horseradish peroxidase (HRP), a typical plant peroxidase. The results showed that DBD plasma caused inactivation of HRP in a time-and discharge power-dependent manner. The HRP activity decreased by $32.5,50.6,65.5$, and $75.4 \%$, respectively, after $2,4,6$, and 8 min of exposure to DBD plasma at 57.6 W. The efficacy of DBD plasma for HRP inactivation was enhanced on increasing the discharge power from 6.0 to $57.6 \mathrm{~W}$. Intrinsic fluorescence spectra showed that DBD plasma induced obvious structural changes in HRP. DBD plasma also caused fragmentation and carbonylation of HRP as well as the oxidative degradation of heme, which might be due to the reactive species in plasma. After DBD plasma exposure at $43.0 \mathrm{~W}$ for $8 \mathrm{~min}$, there was approximately an 8.4-fold increase in surface hydrophobicity of HRP. After exposure to DBD plasma, the aggregation of HRP was observed by using atomic force microscopy analysis. In conclusion, DBD plasma causes structural changes and chemical modification of HRP, which may be responsible for the loss of enzymatic activity. These data contribute to the application of cold plasma in the control of enzymatic browning of food products during processing and storage.
\end{abstract}

Keywords: dielectric barrier discharge plasma; horseradish peroxidase; inactivation; mechanisms

\section{Introduction}

Endogenous enzymes are widely found in fruit and vegetable products, such as polyphenol oxidase (PPO), peroxidase (POD), pectin methylesterase (PME), polygalacturonase (PG), and ascorbate oxidase ( $\mathrm{AO})(\mathrm{Hu}$ et al., 2013). Some endogenous enzymes may cause deterioration in the nutrients, flavor, texture, and color of foods during processing or preservation. POD and PPO are the main enzymes involved in oxidative deterioration reactions, resulting in the browning phenomenon and the loss of antioxidant activity of fruits and vegetables (Hu et al., 2013). Lipoxygenase (LOX), a family of nonheme-iron-containing fatty acid dioxygenases widely found in many plants (e.g., wheat, soybean, mung bean, and pea), can catalyze the oxidation of polyunsaturated fatty acids to yield hydroperoxides, leading to the loss of color, flavor, odor, and other processing qualities of plant-based products (Baysal and Demirdoven, 2007). Thus, these endogenous enzymes associated with quality decay should be inactivated to ensure the nutritional and sensory properties of foods. Traditionally, thermal treatments (e.g., hot water, steam, and microwave blanching) are extensively used to inactivate endogenous enzymes and decrease the microbial load in raw vegetables and fruits during processing operations (Deng et al., 2019). 
However, these thermal methods are known to cause detrimental effects on the nutritional, functional, and sensory properties (Petruzzi et al., 2017). In addition, chemical preservatives (such as sulfur dioxide, sulfites, and citric acid) have also been used to inhibit enzyme activity, but chemical residues pose significant health risks to humans (Lien et al., 2016). Therefore, emerging nonthermal technologies have been developed for the inactivation of deleterious endogenous enzymes and microorganisms in foods, such as high-pressure carbon dioxide, pulsed electric fields, high hydrostatic pressure, and ultrasound (Hu et al., 2013; Wu et al., 2020; Zhang et al., 2019).

In the past few years, the application of cold plasma in the agriculture and food industry has been studied extensively (Liao et al., 2019; Xiang et al., 2018a). Plasma, the fourth state of matter, is an electrically neutral ionized gas, which generally consists of charged ions, electrons, metastable particles (such as excited atoms, molecules, and radicals), and photons (Niveditha et al., 2021). Currently, cold plasma is mainly generated by electrical discharges, for example, dielectric barrier discharge (DBD), corona discharge, gliding arc discharge, spark discharge, and microwave discharge (López et al., 2019). In the past few years, cold plasma has shown good application potential in the food industry, including food decontamination and the elimination of toxic chemical residues as well as food ingredients and food packaging modifications (Gavahian and Khaneghah, 2020; Gavahian et al., 2020; Wang et al., 2020; Xiang et al., 2018b). For instance, Gavahian et al. (2019) found that DBD plasma treatment could effectively retain the textural and visual quality of shiitake mushrooms stored for 1 week.

In addition, cold plasma is also used to inactivate a range of endogenous food enzymes and modify the structure and properties of proteins. Following exposure to plasma-processed air for $10 \mathrm{~min}$, the PPO and POD activities of fresh-cut apple were reduced by approximately 62 and $65 \%$, respectively (Bußler et al., 2017). Similar findings were also reported by Tolouie et al. (2018), who found that the residual activities of lipase and LOX of wheat germ were reduced to $25.03 \%$ and $49.98 \%$ after 25 min of treatment with DBD plasma at $24 \mathrm{kV}$. Peroxidases (PODs), a diverse group of oxidoreductases, are widely found in animals, plants, and microorganisms. PODs can catalyze the oxidoreduction between $\mathrm{H}_{2} \mathrm{O}_{2}$ and various reductants, and play an important role in many biological processes such as organ specificity, stress response, and pathogen infection (Hiraga et al., 2001). According to the literature, class III plant peroxidase (EC 1.11.1.7) can catalyze the oxidation of endogenous phenolic compounds, consequently causing undesirable changes in the color, flavor, texture, and nutritional quality of plantbased foods during processing and storage (Burnette,
1977; Jang and Moon, 2011). Although the cold plasmainduced inactivation of POD has been well investigated (Bußler et al., 2017; Pankaj et al., 2013), the underlying mechanisms are not well clarified.

Based upon previous studies on cold plasma-induced inactivation of endogenous food enzymes, this study aimed to assess the effect of DBD plasma on the inactivation of horseradish peroxidase (HRP) isolated from horseradish (Armoracia rusticana) roots, a typical plant peroxidase. The effect of DBD plasma on the structure and properties of HRP was also investigated by using fluorescence, sodium dodecyl sulfate-polyacrylamide gel electrophoresis (SDS-PAGE), western blot assay, and atomic force microscopy (AFM). The results of the current study could provide a basis for applying cold plasma technology in enzymatic browning inhibition of fruits and vegetables.

\section{Materials and Methods}

\section{Chemicals and reagents}

Horseradish peroxidase (HRP, EC 1.14.18.1, RZ > 3.0) and guaiacol were provided by Shanghai Macklin Biochemical Co., Ltd. (Shanghai, China). Coomassie brilliant blue (CBB) R-250 and 1-anilinonaphthalene-8sulfonate (ANS) were purchased from Aladdin Reagent Co., Ltd. (Shanghai, China). A protein carbonyl assay kit was purchased from Abcam (ab178020, Cambridge, UK). Polyvinylidene fluoride (PVDF) membranes with a pore size of $0.45 \mu \mathrm{m}$ and enhanced chemiluminescence (ECL) substrate were obtained from Millipore Corp. (Bedford, MA, USA).

\section{DBD plasma setup and treatment}

The plasma system consists of a high voltage alternating current (AC) power source (CTP-2000 K), a DBD-50 plasma reactor, a voltage regulator, and a quartz dish (Nanjing Suman Electronics Co., Ltd., China). The two stainless steel electrodes (outer diameter $=53 \mathrm{~mm}$ ) were covered with two 1-mm dielectric quartz plates (the diameters of the upper and lower dielectric discs were 100 and $90 \mathrm{~mm}$, respectively). The distance between the quartz plates was approximately $15 \mathrm{~mm}$. A quartz reactor (outer diameter $=70 \mathrm{~mm}$, inner diameter $50 \mathrm{~mm}$, depth $=$ $4 \mathrm{~mm}$, and height $=8 \mathrm{~mm}$ ) was placed at the center of two dielectric discs (Figure 1). Air was used as the discharge gas (Li et al., 2017). The discharge voltage and current were measured by an oscilloscope (DS1102E, Rigol).

HRP was dissolved in phosphate buffer $(\mathrm{PB}, 100 \mathrm{mmol} / \mathrm{L}$, $\mathrm{pH} 7.0$ ) at a concentration of $0.5 \mathrm{mg} / \mathrm{mL}$. HRP solution 


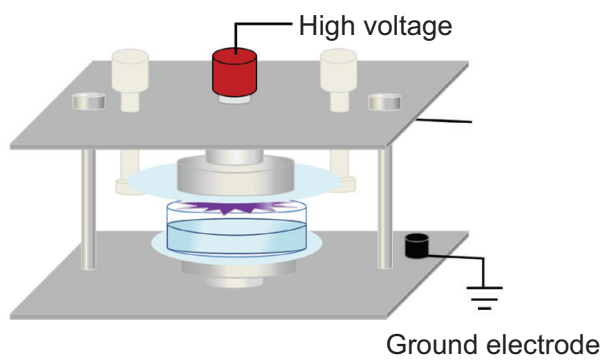

Figure 1. Schematic diagram of the DBD plasma actuator.

$(2 \mathrm{~mL})$ was placed in the quartz reactor and subjected to plasma treatment at different powers $(6.0,26.4,43.0$, and $57.6 \mathrm{~W})$ for the indicated time period.

\section{Determination of enzymatic activity}

The enzymatic activity of HRP was determined by the method of Wang et al. (2017). After each treatment, $90 \mu \mathrm{L}$ of guaiacol solution $(20 \mathrm{mmol} / \mathrm{L}$ in ultrapure water) was mixed with $200 \mu \mathrm{L}$ of $\mathrm{H}_{2} \mathrm{O}_{2}$ solution $(0.25 \%$, $\mathrm{v} / \mathrm{v})$ and $10 \mu \mathrm{L}$ of HRP solution $(0.5 \mathrm{mg} / \mathrm{mL})$. Then, the absorbance was measured at $470 \mathrm{~nm}$ for $180 \mathrm{~s}$ using a Tecan Spark 20M multimode microplate reader (Tecan Group Ltd., Männedorf, Zürich, Switzerland). One unit of enzymatic activity $(\mathrm{U})$ was defined as an increase of 0.001 units of absorbance per minute under the assay conditions. The relative activities of HRP were obtained with the following formula:

$$
\text { Residual activity }=\frac{A}{A_{0}} \times 100 \%
$$

where $A$ is the specific activity of HRP treated with DBD plasma and $A_{0}$ is the initial activity of HRP solution without DBD plasma treatment.

\section{Analysis of intrinsic fluorescence spectra}

Intrinsic fluorescence spectral analysis was conducted using a fluorescence spectrophotometer (F-7100, Hitachi High-Technologies Corp., Tokyo, Japan). In brief, HRP solutions $(0.5 \mathrm{mg} / \mathrm{mL}$ in $100 \mathrm{mmol} / \mathrm{L} \mathrm{PB}, \mathrm{pH} 7.0)$ were excited at $280 \mathrm{~nm}$, and the emission wavelength ranged from 290 to $340 \mathrm{~nm}$ at a scan speed of $240 \mathrm{~nm} / \mathrm{min}$. The emission and excitation slit widths were both adjusted to $5 \mathrm{~nm}$. Fluorescence intensity is measured in arbitrary units (A.U.).

\section{Analysis of protein oxidative damage}

HRP solutions $(0.5 \mathrm{mg} / \mathrm{mL})$ were treated with DBD plasma at $43 \mathrm{~W}$ for $0,2,4,6$, and $8 \mathrm{~min}$, respectively.
Thereafter, the oxidative damage of HRP was assessed by SDS-PAGE (Dong et al., 2021). In brief, each sample was mixed with $4 \times$ sample loading buffer and heated in boiling water for $5 \mathrm{~min}$. Protein samples were separated on $10 \%$ SDS-polyacrylamide gel and the gel was stained with CBB R-250 solution for $1 \mathrm{~h}$ with gentle agitation. Following the destaining step, the gel was visualized by using a ChemiDoc $\mathrm{XRS}^{+}$system (Bio-Rad Laboratories, Hercules, CA, USA). The levels of carbonylated HRP were detected using a protein carbonyl assay kit (ab178020, Abcam) according to the manufacturer's protocols. The immunoreactive proteins were visualized using a chemiluminescence protocol, and the images were recorded with a ChemiDoc $\mathrm{XRS}^{+}$system (Bio-Rad).

\section{Determination of surface hydrophobicity}

The ANS probe was used to determine the surface hydrophobicity index (SHI) of HRP before or after exposure to DBD plasma (Pustulka et al., 2020). The HRP solution (4 mL, $0.2-1.0 \mathrm{mg} / \mathrm{mL}$ ) was added to $20 \mu \mathrm{L}$ of ANS stock solution $(8 \mathrm{mmol} / \mathrm{L}$ in $\mathrm{PB}$ of $100 \mathrm{mmol} / \mathrm{L}, \mathrm{pH} 7.0)$, and then mixed well. After 15 min of incubation in the dark, the relative fluorescence intensity was measured using a HITACHI F-7100 fluorescence spectrometer (Tokyo, Japan) at excitation and emission wavelengths of $390 \mathrm{~nm}$ and $470 \mathrm{~nm}$, respectively. The excitation and emission slit widths were both $5 \mathrm{~nm}$. The slope of the relative fluorescence intensity versus protein concentration plot was calculated by linear regression, and the slope of the initial segment was reported as the $\mathrm{SHI}\left(\mathrm{S}_{0}\right)$.

\section{Atomic force microscopy analysis}

The changes in the molecular microstructure of HRP were further assessed by AFM. After treatment with DBD plasma at $43.0 \mathrm{~W}$ for 0,4 , and $8 \mathrm{~min}, 10 \mu \mathrm{L}$ of HRP solution $(0.5 \mathrm{mg} / \mathrm{mL})$ was dropped onto a freshly cleaved mica surface and air-dried in a clean hood for $1 \mathrm{~h}$ at ambient temperature. Thereafter, the samples were measured by AFM (NanoMan VS, Bruker, Karlsruhe, Germany) in the tapping mode (Wang et al., 2017). Samples were scanned with a force constant of $2 \mathrm{~N} / \mathrm{m}$, a scan rate of $2 \mathrm{~Hz}$, and a step size of 3'3 $3 \mathrm{~m}$. The obtained topographical images were analyzed with NanoScope Analysis 1.7 software (Bruker).

\section{Analysis of heme damage}

HRP solutions $(0.5 \mathrm{mg} / \mathrm{mL})$ were treated with DBD plasma at $43.0 \mathrm{~W}$ for $0,2,4,6$, and $8 \mathrm{~min}$. The absorption spectra of HRP solutions were scanned in the range of 250 to $550 \mathrm{~nm}$ with a UV-Vis spectrophotometer 
(1800PC, Macylab Instruments Inc., Shanghai, China). The fluorescent heme degradation products were analyzed according to a previously described method (Nagababu and Rifkind, 2004). HRP solutions (0.5 mg/ $\mathrm{mL}$ in $100 \mathrm{mmol} / \mathrm{L} \mathrm{PB}, \mathrm{pH} 7.0$ ) were excited at $330 \mathrm{~nm}$, and the emission was collected from 340 to $600 \mathrm{~nm}$ at a scan speed of $240 \mathrm{~nm} / \mathrm{min}$. Both the excitation and emission slit widths were set to $5 \mathrm{~nm}$.

\section{Statistical analysis}

All analyses were carried out in triplicate and experimental results are expressed as the mean \pm standard deviation (SD). The data were analyzed using one-way analysis of variance (ANOVA), and the differences between the means were tested by using the Fisher's least significant difference (LSD) test at $p<0.05$. Statistical analyses were conducted using SPSS Statistics for Windows, Version 22.0 (IBM Corp., Armonk, NY, USA).

\section{Results and Discussion}

\section{Inactivation of HRP induced by DBD plasma}

HRP isolated from horseradish tissue was used in this work. Horseradish (Armoracia rusticana) is a perennial herb of the Brassica mustard family and is cultivated mainly for the culinary value of its pungent roots (Veitch, 2004). A. rusticana roots provide an abundant source of peroxidase, and thus, they are the main source of industrial HRP. The inactivation of HRP by DBD plasma is presented in Figure 2. The initial activity of HRP was $228 \mathrm{U} / \mathrm{mL}$, which decreased continuously as a function of the DBD plasma exposure time. After 2, 4, 6, and 8 min

(A)

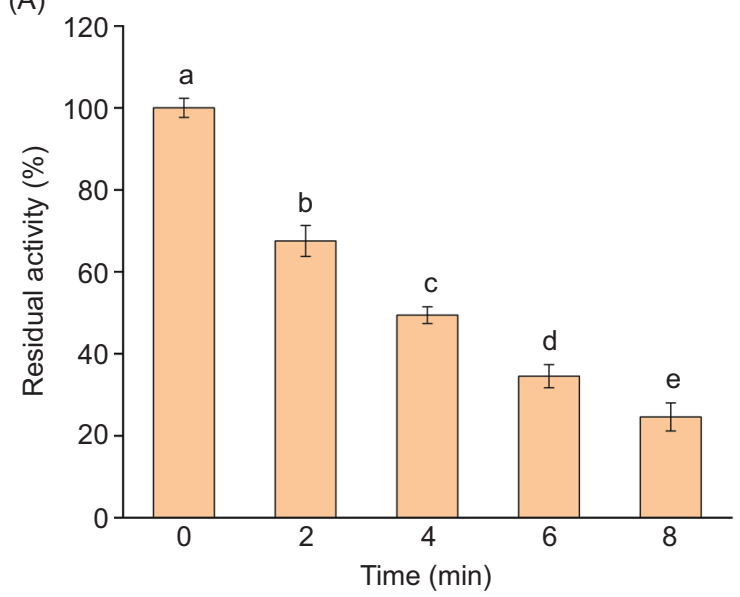

of exposure to DBD plasma at $57.6 \mathrm{~W}$, the HRP activity decreased by $32.5,50.6,65.5$, and $75.4 \%$, respectively (Figure 2A). Similar findings were reported in the studies of Wang et al. (2021), in which the residual activity of POD extracted from litchi pericarp decreased to $47.16 \%$ after DBD plasma treatment for $10 \mathrm{~min}$. Chutia et al. (2019) reported that the DBD plasma treatment time was a significant factor for the inactivation of PPO and POD in tender coconut water. Illera et al. (2019) also reported that spark discharge plasma could effectively inactivate PPO in a pure enzymatic solution or cloudy apple juice in a time-dependent manner.

The discharge power also played a critical role in DBDplasma-mediated HRP inactivation. The residual activities of HRP steadily decreased with increasing discharge power of DBD reaction. The HRP activity decreased by $11.4,12.7,50$, and $75.4 \%$, respectively, after $8 \mathrm{~min}$ of exposure to DBD plasma at 6.0 W, 26.4 W, 43.0 W, and $57.6 \mathrm{~W}$, respectively (Figure 2B). Similar findings were also previously reported by Chutia et al. (2019), who found that greater inactivation efficacy of DBD plasma on PPO and POD in tender coconut water was observed at a higher voltage. This may be because more reactive species were generated during gas-phase plasma discharge supplied with a higher power, which is responsible for the plasma-elicited inactivation effects (Pai et al., 2018).

\section{Intrinsic fluorescence spectra of DBD plasma-treated HRP}

Proteins and peptides exhibit intrinsic fluorescence when excited with UV light, which originates from the three amino acid residues with aromatic side chains:

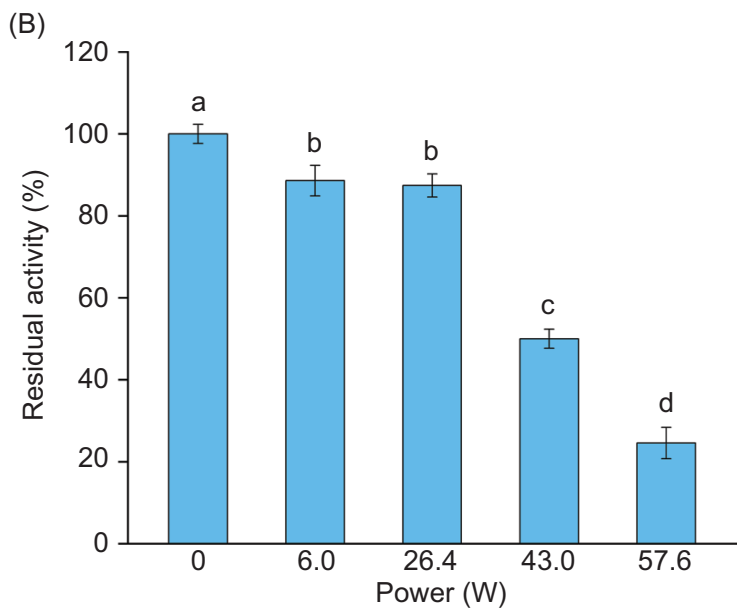

Figure 2. Residual activity of HRP after exposure to DBD plasma. (A) HRP solutions $(0.5 \mathrm{mg} / \mathrm{mL})$ were treated with DBD plasma at $57.6 \mathrm{~W}$ for the indicated time periods. (B) HRP solutions $(0.5 \mathrm{mg} / \mathrm{mL})$ were treated with DBD plasma at the indicated power for $8 \mathrm{~min}$. Values with different letters are significantly different based on the LSD test at $p<0.05$. 
tryptophan (Trp), tyrosine (Tyr), and phenylalanine (Phe). Among the three aromatic amino acids, Trp is regarded as the dominant intrinsic fluorophore of proteins due to its highest quantum yield and largest extinction coefficient (Ghisaidoobe and Chung, 2014). Hence, the intrinsic fluorescence of proteins has been widely used to probe changes in protein structure and therefore function. As depicted in Figure 3, the fluorescence intensity of HRP gradually decreased after exposure to DBD plasma. The initial intrinsic fluorescence of the HRP solution was 6696 A.U. (Figure 3A). After DBD plasma treatment at $43.0 \mathrm{~W}$ for $8 \mathrm{~min}$, the intrinsic fluorescence of the HRP solution decreased to 2553 A.U. (Figure 3A). DBD-plasma-induced decrease in the intrinsic fluorescence of HRP was also affected by the discharge power (Figure 3B). The obvious changes in the fluorescence intensity of HRP might be due to the structural changes in HRP induced by DBD plasma.

The largest emission peak $\left(\lambda_{\max }\right)$ of the native HRP was at $309.4 \mathrm{~nm}$, suggesting that Trp is buried in a "nonpolar" environment (Vivian and Callis, 2001). Slight changes were observed in $\lambda_{\max }$ after DBD plasma treatment. After DBD plasma treatment at $43.0 \mathrm{~W}$ for $8 \mathrm{~min}$, the $\lambda_{\text {max }}$ of HRP was red-shifted to $311.4 \mathrm{~nm}$ (Figure 3A). These data indicated that Trp residues of HRP moved to the outside of the protein molecules, causing an increase in the polarity of their local microenvironment (Jiang et al., 2014). These data reflect the changes in the three-dimensional structures and conformation of HRP after exposure to DBD plasma, which may be responsible for the loss of enzyme activity.

\section{DBD plasma caused oxidation and carbonylation of HRP}

The oxidative degradation of HRP induced by DBD plasma was monitored by SDS-PAGE under reducing

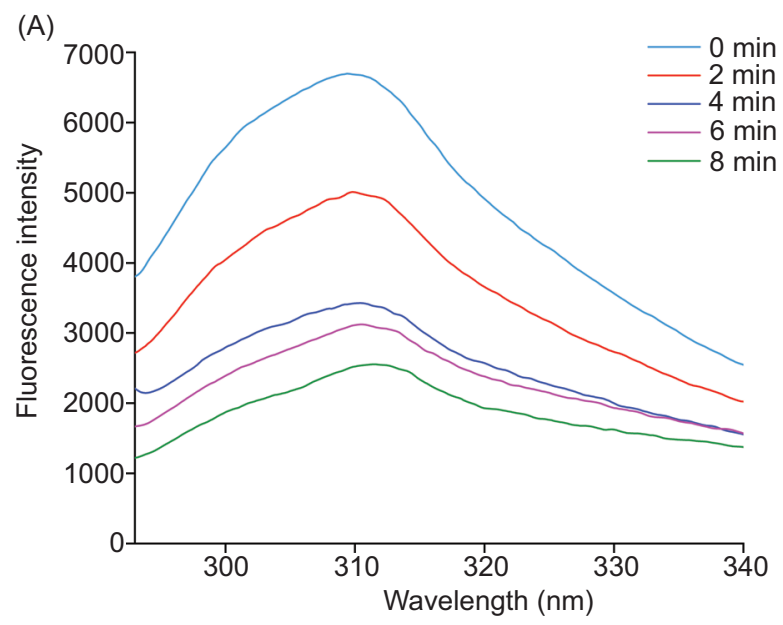

conditions. As depicted in Figure 4A, a distinct HRP band was observed approximately at $43 \mathrm{kD}$. The intensity of HRP bands decreased in a time-dependent manner after DBD plasma treatment (Figure 4A). These data are consistent with previous findings ( $\mathrm{Ng}$ et al., 2020; Venkataratnam et al., 2020). For instance, SDSPAGE analysis indicated that the band intensity of casein declined dramatically with an increasing treatment time of spark discharge and glow discharge plasma (Ng et al., 2020). Similar findings were also reported by Venkataratnam et al. (2020), who found that cold plasma caused degradation of Ara h1 and Ara h2 with SDSPAGE, two major peanut allergens. The decrease in band intensity following DBD plasma treatment may be due to the oxidative damage of HRP. During gas discharge, various active molecules are generated, such as charged particles, energetic ions, reactive species (e.g., ozone, hydroxyl radicals, superoxide, peroxide, and nitric oxide radicals), and ultraviolet (UV) radiation (Gaunt et al., 2006). These species may lead to the cleavage of peptide bonds, resulting in the fragmentation of HRP as indicated by the arrow in Figure 4A.

The formation of carbonyl groups is the most widely used marker of protein oxidation. In this work, carbonylated HRP was measured by western blot assay using a protein carbonyl assay kit (ab178020, Abcam). As shown in Figure 4B, obvious carbonylated HRP bands were observed after exposure to DBD plasma at 43.0 W for $8 \mathrm{~min}$. Similar findings were also observed in the studies of Attri et al. (2015) and Panpipat and Chaijan (2020), who stated that the carbonyl contents of hemoglobin, myoglobin, and actomyosin from threadfin bream were remarkably increased after being subjected to cold plasma. Reactive carbonyl derivatives (e.g., aldehydes, ketones, and lactams) can be generated through oxidative

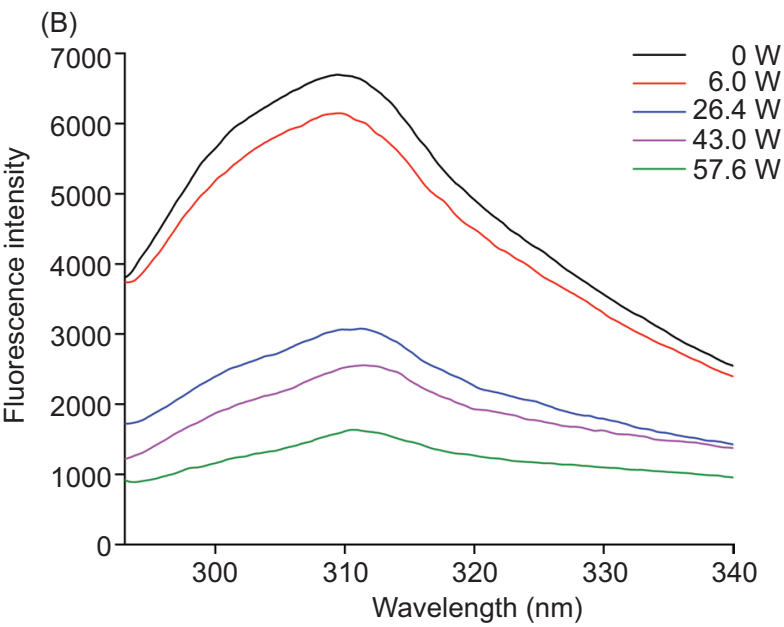

Figure 3. Fluorescence emission spectra of HRP after DBD plasma treatment. (A) HRP solutions were treated with DBD plasma at $43.0 \mathrm{~W}$ for the indicated time. (B) HRP solutions were treated with DBD plasma at $6.0,26.4,43.0$, and $57.6 \mathrm{~W}$ for $8 \mathrm{~min}$, respectively. 
(A)

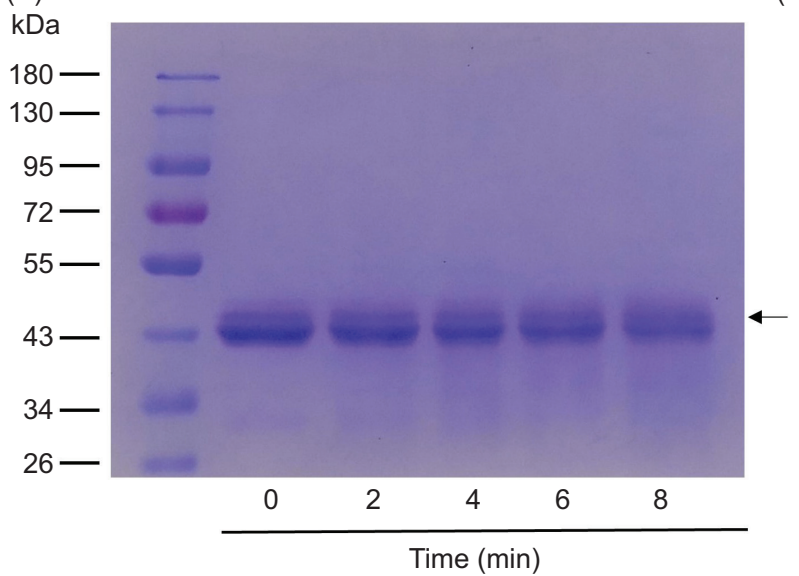

(B)

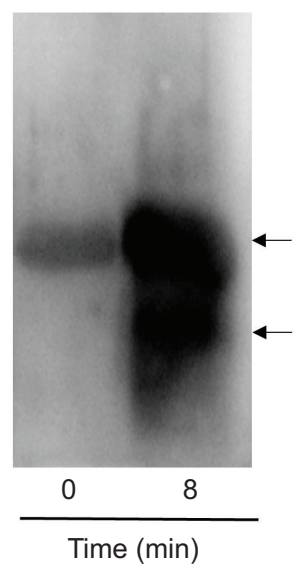

Figure 4. Oxidative damage of HRP after DBD plasma treatment at $43.0 \mathrm{~W}$ for the indicated time. (A) SDS-PAGE patterns of HRP treated with DBD plasma. (B) Analysis of carbonylated HRP with western blot assay.

cleavage of the protein backbone or modification of amino acid side chains induced by free radicals (Fedorova et al., 2014). As indicated by the arrow in Figure 4B, the immunoreactive bands were also observed in the lower molecular weight region of the western blot, suggesting that the oxidative degradation of HRP was caused by the active molecules in DBD plasma. These data reveal that the reactive species in DBD plasma may induce modification of amino acid side chains or backbone cleavage in HRP molecules, which may subsequently result in the loss of enzymatic activity.

\section{Effect of DBD plasma on the surface hydrophobicity of HRP}

Surface hydrophobicity is an important surface-related property of proteins. The effect of DBD plasma on the surface hydrophobicity of HRP is shown in Figure 5. The $\mathrm{S}_{0}$ values for HRP were significantly increased as a function of DBD plasma treatment time $(p<0.05)$. After exposure to DBD plasma at $43.0 \mathrm{~W}$ for $8 \mathrm{~min}$, the $S_{0}$ value of HRP increased to 2245.75 , which was significantly higher than that of the native protein molecule. These data were in agreement with those reported in previous works. Segat et al. (2015) found that the surface hydrophobicity of whey protein isolate increased after exposure to DBD plasma for 1 to $30 \mathrm{~min}$ but decreased remarkably as the treatment time increased to $60 \mathrm{~min}$.

The surface hydrophobicity of proteins is determined by various factors, such as the size, shape, amino acid composition and sequence, and the intramolecular or intermolecular cross-linking of proteins (Jiang et al., 2015). The increased surface hydrophobicity might be due to the structural unfolding of HRP after exposure to DBD plasma. During DBD plasma treatment, the hydrophobic

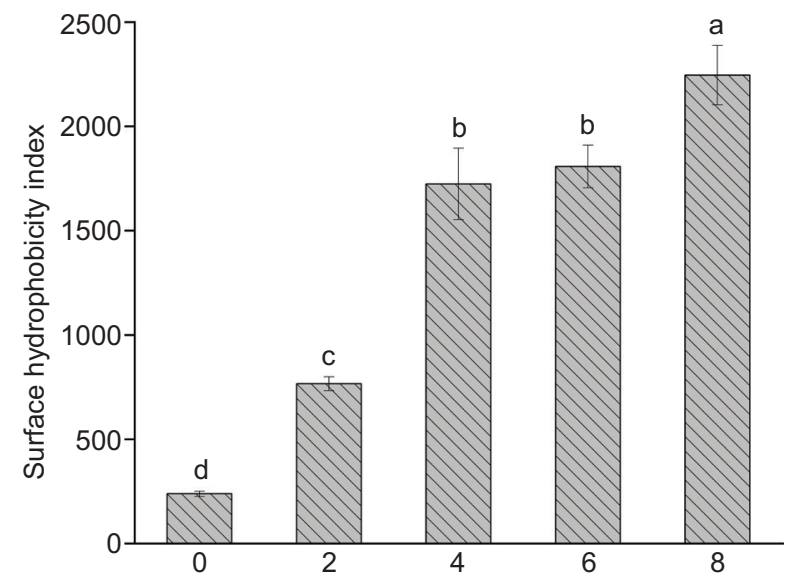

Figure 5. Surface hydrophobicity of HRP after exposure to DBD plasma at $43.0 \mathrm{~W}$ for the indicated time periods. Means followed by different letters are significantly different $(p<$ 0.05) according to the LSD test.

amino acids buried within the protein molecule might become more hydrophobic on the surface of the protein, where they were more accessible to the ANS probes (Segat et al., 2015). In addition, DBD-plasma-induced oxidative degradation of HRP may also contribute to changes in the surface hydrophobicity (Jiang et al., 2015).

\section{Particle size analysis of HRP by AFM}

The AFM images of HRP before and after DBD plasma treatment are displayed in Figure 6A. The native HRP particles on the mica surface were uniform with an average diameter of $106 \mathrm{~nm}$, and the average height was $12 \mathrm{~nm}$. As depicted in Figure 6A, particulate aggregates of HRP proteins were observed after exposure to DBD plasma. After DBD plasma treatment at $43.0 \mathrm{~W}$ for 
(A)
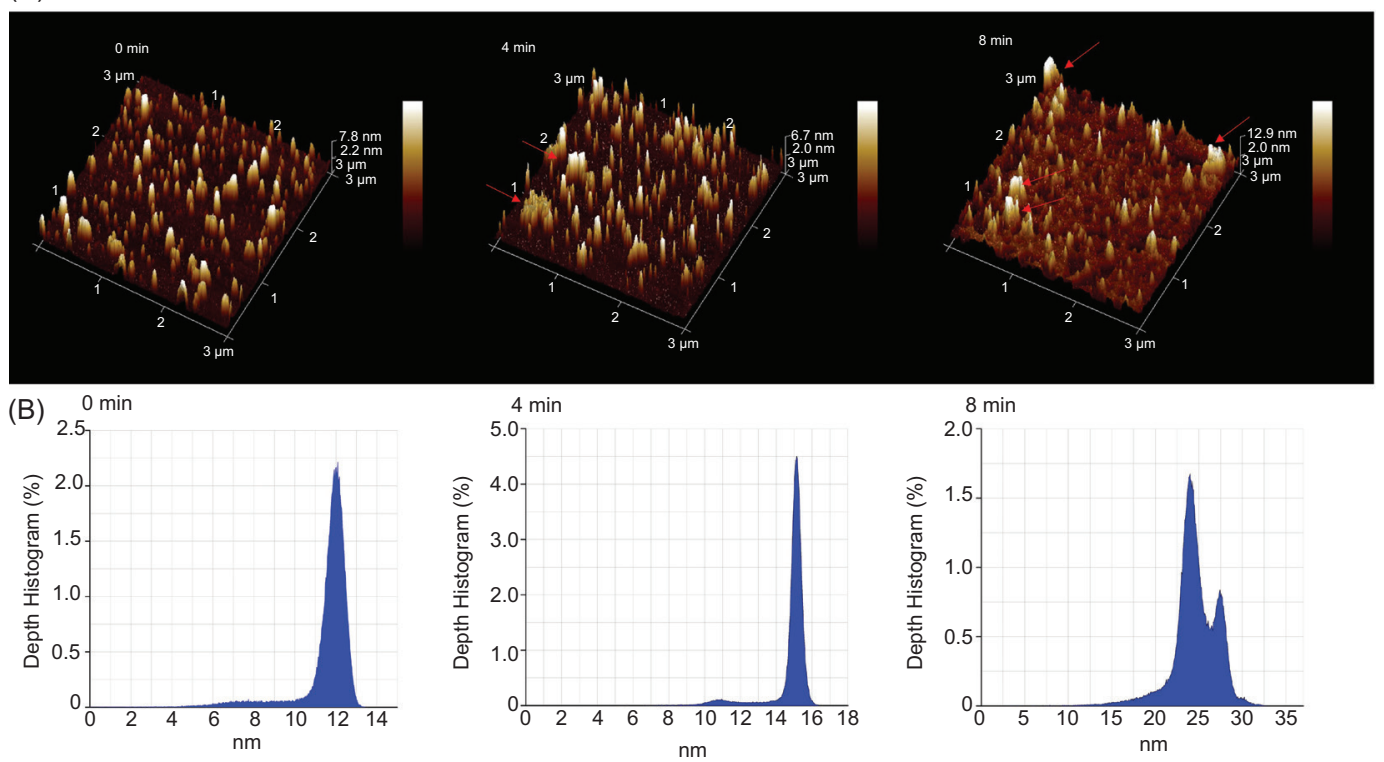

Figure 6. AFM topography images (A) and height distribution of HRP (B) before or after DBD plasma treatment at $43.0 \mathrm{~W}$ for 0 , 4 , and 8 min.

4 and $8 \mathrm{~min}$, the average diameter of HRP particles was increased to 147 and $229 \mathrm{~nm}$, respectively (Figure 6A). In addition, as shown in Figure 6B, after exposure to DBD plasma, the average height was remarkably increased, and the average height was increased to 15 and $25 \mathrm{~nm}$ after DBD plasma treatment at $43.0 \mathrm{~W}$ for 4 and $8 \mathrm{~min}$, respectively.

Similar aggregation was also reported for HRP, thaumatin-like proteins, and PPO treated with pulsed light (Wang et al., 2017), high-pressure carbon dioxide (Li et al., 2014), and heat (Zhou et al., 2017). AFM analysis revealed that the aggregation of enzyme proteins increased after exposure to pulsed light (Wang et al., 2017). DBD plasma caused denaturation and aggregation of HRP, which might contribute to the loss of enzymatic activity (Zhou et al., 2017).

\section{DBD plasma caused damages to heme}

HRP has two metal centers, one heme group and two calcium atoms. The heme group is located at the catalytic reaction center of HRP and plays an important role in maintaining the three-dimensional structure of the enzyme (Veitch, 2004). The characteristic structures of HRP before or after plasma exposure were determined by measuring UV-visible spectroscopy. As shown in Figure 7A, native HRP showed a Soret band at $403 \mathrm{~nm}$, corresponding to the presence of the heme group. After exposure to DBD plasma, the Soret band at $403 \mathrm{~nm}$ significantly increased in a time-dependent manner. This indicates that DBD plasma causes extensive conformational changes in the protein molecule.

The detrimental effect of DBD plasma on the heme group was also analyzed by measuring the fluorescent heme degradation products. As shown in Figure $7 \mathrm{~B}$, native HRP displayed the largest emission peaks at $425 \mathrm{~nm}$ with a fluorescence intensity of 1045 A.U. However, DBD plasma caused remarkable increases in the fluorescence intensity of HRP. After exposure to DBD plasma at 43.0 W for $8 \mathrm{~min}$, the fluorescence intensity of HRP increased to 6259 A.U., while no shift was observed. The elevated fluorescence intensity may be due to the oxidative degradation of heme caused by RONS, such as $\mathrm{H}_{2} \mathrm{O}_{2}$, in the air DBD plasma. Previous studies show that fluorescent products are formed during the reaction of heme and hemin with hydroperoxides, including $\mathrm{H}_{2} \mathrm{O}_{2}$, cumene hydroperoxide, and tertiary butyl hydroperoxides. In addition, the release of iron from the heme moiety is also observed from the reaction of heme and hydroperoxides (Nagababu and Rifkind, 2004). These data suggest that the chemically active species causes extensive conformational changes in the HRP molecule, consequently resulting in loss of enzymatic activity.

\section{Conclusions}

The present study reported the inactivation effect and mechanisms of DBD plasma on HRP. A significant loss of HRP activity was observed after DBD plasma treatment, which was affected by the exposure time 
(A)

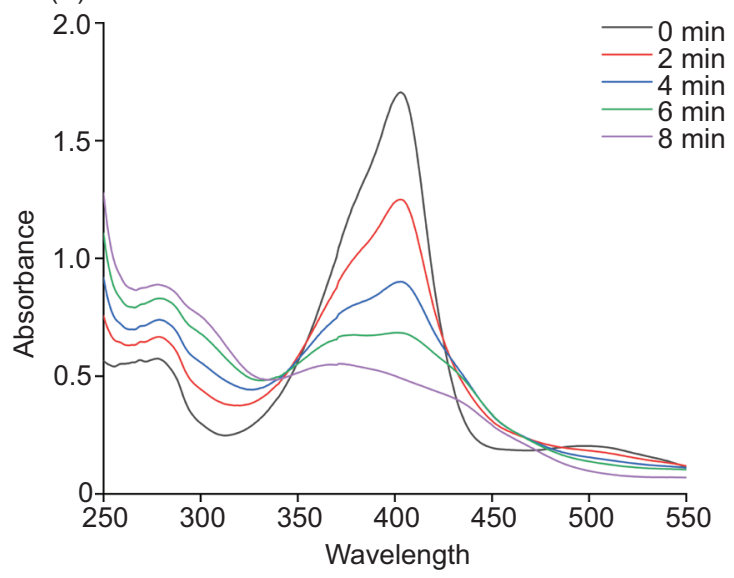

(B)

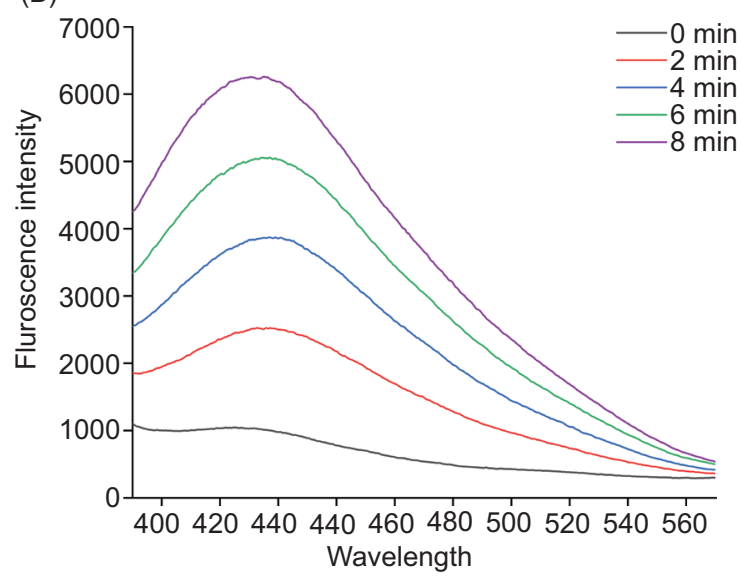

Figure 7. Detrimental effects of DBD plasma treatment on the heme group in HRP. (A) UV-visible absorption spectra of HRP solution $(0.5 \mathrm{mg} / \mathrm{mL})$ after DBD plasma treatment at $43.0 \mathrm{~W}$ for the indicated time periods. (B) Formation of fluorescent heme degradation products during the reaction of HRP with DBD plasma at $43.0 \mathrm{~W}$ for $0,2,4,6$, and $8 \mathrm{~min}$, respectively.

and discharge power. DBD plasma caused remarkable changes in the three-dimensional structure or conformation of the protein. In addition, fragmentation and carbonylation of HRP as well as the oxidative degradation of heme were also observed after exposure to DBD plasma, which might be due to the reactive species in plasma. AFM analysis of HRP suggested that DBD plasma induced aggregation of HRP. These data indicate that the HRP inactivation induced by DBD plasma is mainly due to the structural changes and oxidative modification of the protein molecule. In summary, cold plasma is a promising new technology to inhibit the enzymatic browning of fruits and vegetables. However, cold plasma technology is still in its infancy, and several technological challenges need to be solved before its industrial application, such as the scale-up of plasma-generating devices and the optimization of processing parameters. In addition, the influences of cold plasma on the quality of food products and human health should be well evaluated before this technology can be fully utilized.

\section{Conflicts of Interest}

The authors declare no conflicts of interest.

\section{Acknowledgments}

This work was financially supported by the National Natural Science Foundation of China-Henan Joint Fund (No. U1704113) and the Natural Science Foundation of Henan Province (No. 212300410090).

\section{References}

Attri, P., Kumar, N., Park, J.H., Yadav, D.K., Choi, S., Uhm, H.S., et al., 2015. Influence of reactive species on the modification of biomolecules generated from the soft plasma. Scientific Reports 5: 8221 . https://doi.org/10.1038/srep08221

Baysal, T. and Demirdoven, A., 2007. Lipoxygenase in fruits and vegetables: a review. Enzyme and Microbial Technology 40: 491-496. https://doi.org/10.1016/j.enzmictec.2006.11.025

Bußler, S., Ehlbeck, J. and Schlüter, O.K., 2017. Pre-drying treatment of plant related tissues using plasma processed air: impact on enzyme activity and quality attributes of cut apple and potato. Innovative Food Science \& Emerging Technologies 40: 78-86. https://doi.org/10.1016/j.ifset.2016.05.007

Burnette, F.S., 1977. Peroxidase and its relationship to food flavor and quality: a review. Journal of Food Science 42: 1-6. https:// doi.org/10.1111/j.1365-2621.1977.tb01204.x

Chutia, H., Kalita, D., Mahanta, C.L., Ojah, N. and Choudhury, A.J., 2019. Kinetics of inactivation of peroxidase and polyphenol oxidase in tender coconut water by dielectric barrier discharge plasma. LWT-Food Science and Technology 101: 625-629. https://doi.org/10.1016/j.lwt.2018.11.071

Deng, L.Z., Mujumdar, A.S., Zhang, Q., Yang, X.H., Wang, J., Zheng, Z.A., et al., 2019. Chemical and physical pretreatments of fruits and vegetables: effects on drying characteristics and quality attributes-a comprehensive review. Critical Reviews in Food Science and Nutrition 59: 1408-1432. https://doi.org/10.1 080/10408398.2017.1409192

Dong, S.S., Fan, L.M., Ma, Y.F., Du, J. and Xiang, Q.S., 2021. Inactivation of polyphenol oxidase by dielectric barrier discharge (DBD) plasma: kinetics and mechanisms. LWT-Food Science and Technology 145: 111322. https://doi.org/10.1016/j. lwt.2021.111322

Fedorova, M., Bollineni, R.C. and Hoffmann, R., 2014. Protein carbonylation as a major hallmark of oxidative damage: update of 
analytical strategies. Mass Spectrometry Reviews 33: 79-97. https://doi.org/10.1002/mas.21381

Gaunt, L.F., Beggs, C.B. and Georghiou, G.E., 2006. Bactericidal action of the reactive species produced by gas-discharge nonthermal plasma at atmospheric pressure: a review. IEEE Transactions on Plasma Science 34: 1257-1269. https://doi. org/10.1109/TPS.2006.878381

Gavahian, M. and Khaneghah, A.M., 2020. Cold plasma as a tool for the elimination of food contaminants: recent advances and future trends. Critical Reviews in Food Science and Nutrition 60(9): 1581-1592. https://doi.org/10.1080/10408398.2019.1584600

Gavahian, M., Meng-Jen, T. and Khaneghah, A.M., 2020. Emerging techniques in food science: the resistance of chlorpyrifos pesticide pollution against arc and dielectric barrier discharge plasma. Quality Assurance and Safety of Crops \& Foods 12(SP1): 9-17. https://doi.org/10.15586/qas.v12iSP1.807

Gavahian, M., Sheu, F.H., Tsai, M.J. and Chu, Y.H., 2019. The effects of dielectric barrier discharge plasma gas and plasma-activated water on texture, color, and bacterial characteristics of shiitake mushroom. Journal of Food Processing and Preservation 44(1): e14316. https://doi.org/10.1111/jfpp.14316

Ghisaidoobe, A.B.T. and Chung, S.J., 2014. Intrinsic tryptophan fluorescence in the detection and analysis of proteins: a focus on Forster resonance energy transfer techniques. International Journal of Molecular Sciences 15: 22518-22538. https://doi. org/10.3390/ijms151222518

Hiraga, S., Sasaki, K., Ito, H., Ohashi, Y. and Matsui, H., 2001. A large family of class III plant peroxidases. Plant \& Cell Physiology 42: 462-468. https://doi.org/10.1093/pcp/pce061

Hu, W.F., Zhou, L.Y., Xu, Z.Z., Zhang, Y. and Liao, X.J., 2013. Enzyme inactivation in food processing using high pressure carbon dioxide technology. Critical Reviews in Food Science and Nutrition 53: 145-161. https://doi.org/10.1080/10408398.2010. 526258

Illera, A.E., Chaple, S., Sanz, M.T., Ng, S., Lu, P., Jones, J., et al., 2019. Effect of cold plasma on polyphenol oxidase inactivation in cloudy apple juice and on the quality parameters of the juice during storage. Food Chemistry-X 3: 100049. https://doi. org/10.1016/j.fochx.2019.100049

Jang, J.H. and Moon, K.D., 2011. Inhibition of polyphenol oxidase and peroxidase activities on fresh-cut apple by simultaneous treatment of ultrasound and ascorbic acid. Food Chemistry 124: 444-449. https://doi.org/10.1016/j.foodchem.2010.06.052

Jiang, L.Z., Wang, Z.J., Li, Y., Meng, X.H., Sui, X.N., Qi, B.K. and Zhou, L.Y., 2015. Relationship between surface hydrophobicity and structure of soy protein isolate subjected to different ionic strength. International Journal of Food Properties 18: 10591074. https://doi.org/10.1080/10942912.2013.865057

Jiang, L.Z., Wang, Z.J., Li, Y., Wang, Z.J., Liang, J., Wang, R., et al., 2014. Effects of ultrasound on the structure and physical properties of black bean protein isolates. Food Research International 62: 595-601. https://doi.org/10.1016/j.foodres.2014.04.022

Li, J.G., Xiang, Q.S., Liu, X.F., Ding, T., Zhang, X.S., Zhai, Y.F. and Bai, Y.H., 2017. Inactivation of soybean trypsin inhibitor by dielectric-barrier discharge (DBD) plasma. Food Chemistry 232: 515-522. https://doi.org/10.1016/j.foodchem.2017.03.167
Li, R.J., Wang, Y.T., Hu, W.F. and Liao, X.J. 2014. Changes in the activity, dissociation, aggregation, and the secondary and tertiary structures of a thaumatin-like protein with a high polyphenol oxidase activity induced by high pressure $\mathrm{CO}_{2}$. Innovative Food Science \& Emerging Technologies 23: 68-78. https://doi. org/10.1016/j.ifset.2014.02.013

Liao, X.Y., Muhannnnad, A.I., Chen, S.G., Hu, Y.Q., Ye, X.Q., Liu, D.H., et al., 2019. Bacterial spore inactivation induced by cold plasma. Critical Reviews in Food Science and Nutrition 59: 2562-2572. https://doi.org/10.1080/10408398.2018.1460797

Lien, K.W., Hsieh, D.P.H., Huang, H.Y., Wu, C.H., Ni, S.P. and Ling, M.P., 2016. Food safety risk assessment for estimating dietary intake of sulfites in the Taiwanese population. Toxicology Reports 3: 544-551. https://doi.org/10.1016/j. toxrep.2016.06.003

López, M., Calvo, T., Prieto, M., Múgica-Vidal, R., Muro-Fraguas, I., Alba-Elías, F. and Alvarez-Ordonez, A., 2019. A review on non-thermal atmospheric plasma for food preservation: mode of action, determinants of effectiveness, and applications. Frontiers in Microbiology 10: 622. https://doi.org/10.3389/ fmicb.2019.00622

Nagababu, E. and Rifkind, J.M., 2004. Heme degradation by reactive oxygen species. Antioxidants \& Redox Signaling 6: 967-978. https://doi.org/10.1089/1523086042259823

Ng, S.W., Lu, P., Rulikowska, A., Boehm, D., O’Neill, G. and Bourke, P., 2020. The effect of atmospheric cold plasma treatment on the antigenic properties of bovine milk casein and whey proteins. Food Chemistry 342: 128283. https://doi.org/10.1016/j. foodchem.2020.128283

Niveditha, A., Pandiselvam, R., Prasath V.A., Singh, S.K., Gul K. and Kothakota, A., 2021. Application of cold plasma and ozone technology for decontamination of Escherichia coli in foods-a review. Food Control 130: 108338. https://doi.org/10.1016/j. foodcont.2021.108338

Pai, K., Timmons, C., Roehm, K.D., Ngo, A., Narayanan, S.S., Ramachandran, A., Jacob, J.D., et al., 2018. Investigation of the roles of plasma species generated by surface dielectric barrier discharge. Scientific Reports 8: 16674. https://doi.org/10.1038/ s41598-018-35166-0

Pankaj, S.K., Misra, N.N. and Cullen, P.J., 2013. Kinetics of tomato peroxidase inactivation by atmospheric pressure cold plasma based on dielectric barrier discharge. Innovative Food Science \& Emerging Technologies 19: 153-157. https://doi.org/10.1016/j. ifset.2013.03.001

Panpipat, W. and Chaijan, M., 2020. Effect of atmospheric pressure cold plasma on biophysical properties and aggregation of natural actomyosin from threadfin bream (Nemipterus bleekeri). Food and Bioprocess Technology 13: 851-859. https://doi. org/10.1007/s11947-020-024.1-w

Petruzzi, L., Campaniello, D., Speranza, B., Corbo, M.R., Sinigaglia, M. and Bevilacqua, A., 2017. Thermal treatments for fruit and vegetable juices and beverages: a literature overview. Comprehensive Reviews in Food Science and Food Safety 16: 668-691. https://doi.org/10.1111/1541-4337.12270

Pustulka, S.M., Ling, K., Pish, S. and Champion, J.A., 2020. Protein nanoparticle charge and hydrophobicity govern protein corona 
and macrophage uptake. ACS Applied Materials \& Interfaces 12: 48284-48295. https://doi.org/10.1021/acsami.0c12341

Segat, A., Misra, N.N., Cullen, P.J. and Innocente, N., 2015. Atmospheric pressure cold plasma (ACP) treatment of whey protein isolate model solution. Innovative Food Science \& Emerging Technologies 29: 247-254. https://doi.org/10.1016/j. ifset.2015.03.014

Tolouie, H., Mohammadifar, M.A., Ghomi, H., Yaghoubi, A.S. and Hashemi, M., 2018. The impact of atmospheric cold plasma treatment on inactivation of lipase and lipoxygenase of wheat germs. Innovative Food Science \& Emerging Technologies 47: 346-352. https://doi.org/10.1016/j.ifset.2018.03.002

Veitch, N.C., 2004. Horseradish peroxidase: a modern view of a classic enzyme. Phytochemistry 65: 249-259. https://doi. org/10.1016/j.phytochem.2003.10.022

Venkataratnam, H., Cahill, O., Sarangapani, C., Cullen, P.J. and Barry-Ryan, C., 2020. Impact of cold plasma processing on major peanut allergens. Scientific Reports 10: 17038. https://doi. org/10.1038/s41598-020-72636-w

Vivian, J.T. and Callis, P.R., 2001. Mechanisms of tryptophan fluorescence shifts in proteins. Biophysical Journal 80: 2093-2109. https://doi.org/10.1016/S0006-3495(01)76183-8

Wang, B., Zhang, Y.Y., Venkitasamy, C., Wu, B.G., Pan, Z.L. and Ma, H.L., 2017. Effect of pulsed light on activity and structural changes of horseradish peroxidase. Food Chemistry 234: 20-25. https://doi.org/10.1016/j.foodchem.2017.04.149

Wang, X.Y., Wang, S.H., Yan, Y.Z., Wang, W.J., Zhang, L.H. and Zong, W., 2020. The degradation of Alternaria mycotoxins by dielectric barrier discharge cold plasma. Food Control 117: 107333. https://doi.org/10.1016/j.foodcont.2020.107333
Wang, Y.J., Ye, Z.C., Li, J.H., Zhang, Y., Guo, Y.X. and Cheng, J.H. 2021. Effects of dielectric barrier discharge cold plasma on the activity, structure and conformation of horseradish peroxidase (HRP) and on the activity of litchi peroxidase (POD). LWT-Food Science and Technology 141: 111078. https://doi.org/10.1016/j. lwt.2021. 111078

Wu, D., Forghani, F., Daliri, E.B.M., Li, J., Liao, X.Y., et al., 2020. Microbial response to some nonthermal physical technologies. Trends in Food Science \& Technology 95: 107-117. https://doi. org/10.1016/j.tifs.2019.11.012

Xiang, Q.S., Liu, X.F., Li, J.G., Ding, T., Zhang, H., Zhang, X.S. and Bai, Y.H., 2018a. Influences of cold atmospheric plasma on microbial safety, physicochemical and sensorial qualities of meat products. Journal of Food Science and Technology 55: 846-857. https://doi.org/10.1007/s13197-017-3020-y

Xiang, Q.S., Liu, X.F., Li, J.G., Liu, S.N., Zhang, H. and Bai, Y.H., 2018b. Effects of dielectric barrier discharge plasma on the inactivation of Zygosaccharomyces rouxii and quality of apple juice. Food Chemistry 254: 201-207. https://doi.org/10.1016/j. foodchem.2018.02.008

Zhang, Z.H., Wang, L.H., Zeng, X.A., Han, Z. and Brennan, C.S., 2019. Non-thermal technologies and its current and future application in the food industry: a review. International Journal of Food Science \& Technology 54: 1-13. https://doi.org/10.1111/ ijfs.13903

Zhou, L., Liu, W., Zou, L.Q., Xiong, Z.Q., Hu, X.T. and Chen, J., 2017. Aggregation and conformational change of mushroom (Agaricus bisporus) polyphenoloxidase subjected to thermal treatment. Food Chemistry 214: 423-431. https://doi. org/10.1016/j.foodchem.2016.07.04.1 